\title{
The fibrous form of intracellular inclusion bodies in recombinant variant fibrinogen-producing cells is specific to the hepatic fibrinogen storage disease-inducible variant fibrinogen
}

\author{
Shinpei Arai, ${ }^{\mathrm{a}, \mathrm{b}}$ Naoko Ogiwara, ${ }^{\mathrm{b}}$ Saki Mukai, ${ }^{\mathrm{b}}$ Yuka Takezawa, ${ }^{\mathrm{b}}$ Mitsutoshi Sugano, \\ Takayuki Honda, ${ }^{a}$ Nobuo Okumura ${ }^{\mathrm{c}}$ \\ ${ }^{a}$ Department of Laboratory Medicine, Graduate School of Medicine, Shinshu \\ University, Matsumoto, Japan \\ ${ }^{\mathrm{b}}$ Department of Laboratory Medicine, Shinshu University Hospital, Matsumoto, Japan \\ ${ }^{c}$ Department of Health and Medical Sciences, Graduate School of Medicine, Shinshu \\ University, Matsumoto, Japan
}

Address correspondence to:

Nobuo Okumura, Ph.D.

Laboratory of Clinical Chemistry and Immunology

Department of Biomedical Laboratory Sciences

School of Health Sciences

Shinshu University

3-1-1 Asahi, Matsumoto 390-8621, Japan

Tel.: 81-263-37-2392

Fax: 81-263-37-2370

E-mail: nobuoku@shinshu-u.ac.jp

\section{Running head: Cell lines for fibrinogen storage disease}

Article type: Original article

Presented in part in abstract form at the 57th Annual Meeting of the American Society of Hematology, Orlando, December 7, 2015.

This work was supported by JSPS KAKENHI Grant Number 26460672 (N Okumura)

Word count: Abstract; 195

Manuscript; 5,577 (excluding Title page, Tables, and Figures)

Tables: 2, Supplement Table: 1, Figures: 6, Supplement Figure: 1, References: 31 


\section{Abstract}

Fibrinogen storage disease (FSD) is a rare disorder that is characterized by the accumulation of fibrinogen in hepatocytes and induces liver injury. Six mutations in the $\gamma \mathrm{C}$ domain $(\gamma \mathrm{G} 284 \mathrm{R}, \gamma \mathrm{T} 314 \mathrm{P}, \gamma \mathrm{D} 316 \mathrm{~N}$, the deletion of $\gamma \mathrm{G} 346-\mathrm{Q} 350, \gamma \mathrm{G} 366 \mathrm{~S}$, and $\gamma \mathrm{R} 375 \mathrm{~W}$ ) have been identified for FSD. Our group previously established $\gamma 375 \mathrm{~W}$ fibrinogen-producing Chinese hamster ovary $(\mathrm{CHO})$ cells and observed aberrant large granular and fibrous forms of intracellular inclusion bodies. The aim of the present study was to investigate whether fibrous intracellular inclusion bodies are specific to FSD-inducible variant fibrinogen. Thirteen expression vectors encoding the variant $\gamma$-chain were stably or transiently transfected into $\mathrm{CHO}$ cells expressing normal fibrinogen $\mathrm{A} \alpha$ - and $\mathrm{B} \beta$-chains or $\mathrm{HuH}-7$ cells, which were then immunofluorescently stained. Six $\mathrm{CHO}$ and $\mathrm{HuH}-7$ cell lines that transiently produced FSD-inducible variant fibrinogen presented the fibrous (3.2-22.7\% and 2.1-24.5\%, respectively) and large granular (5.4-25.5\% and 7.7-23.9\%) forms of intracellular inclusion bodies. Seven CHO and $\mathrm{HuH}-7$ cell lines that transiently produced FSD-non-inducible variant fibrinogen only exhibits the large granular form. These results demonstrate that transiently transfected variant fibrinogen-producing $\mathrm{CHO}$ cells and inclusion bodies of the fibrous form may be useful in non-invasive screening for FSD risk factors for FSD before its 
onset.

Key Words: intracellular inclusion bodies, hypofibrinogenemia, fibrinogen storage disease, immunofluorescence, recombinant fibrinogen 


\section{Introduction}

Fibrinogen is a $340 \mathrm{kDa}$ and hexameric plasma glycoprotein that is synthesized by hepatocytes and consists of a double set of three polypeptide chains, $A \alpha, B \beta$, and $\gamma$, which are coded by the $F G A, F G B$, and $F G G$ genes, respectively [1,2]. Circulating fibrinogen concentrations range between 1.8 and $3.5 \mathrm{~g} / \mathrm{L}$, and congenital fibrinogen disorders are characterized by functional and antigenic fibrinogen concentrations; patients with lower levels or under detection limit of functional and antigen fibrinogen are fibrinogen deficient (type I; afibrinogenemia as a homozygote and hypofibrinogenemia as a heterozygote), while those with lower levels of functional fibrinogen and a normal level of antigenic fibrinogen have dysfunctional fibrinogenemia (type II; a homozygote and heterozygote) [3]. Almost 200 genetic abnormalities in patients with afibrinogenemia or hypofibrinogenemia have been detected in all three genes and identified as missense, nonsense, or frameshift mutations; splice-site abnormalities; or large deletions, as listed in the fibrinogen variant database [updated on 22/06/2016, http://site.geth.org/site/Pratiques-Professonnelles/Base-de-donnees-Fibrinogene/Databas e-English-Version/Fibrinogen-variants-Database- 79 .html].

Patients with afibrinogenemia or hypofibrinogenemia exhibit bleeding, recurrent 
miscarriages, and peripartum hemorrhages [3]. Only six hypofibrinogenemic variants are located in the $\gamma \mathrm{C}$ domain $(\gamma \mathrm{G} 284-\gamma \mathrm{G} 375)$ and 14 families have been diagnosed with fibrinogen storage disease (FSD), which accumulates the variant fibrinogen within the endoplasmic reticulum (ER) of hepatocytes and induces liver injury. FSD associated with hypofibrinogenemia was initially reported in Italian patients with the $\gamma$ G284R variant [4] and another family with the same type of variant was recently identified in Germany [5]. Five more heterozygous $\gamma$-chain variant fibrinogen types have been found in the $\gamma \mathrm{C}$ domain ( $\gamma \mathrm{T} 314 \mathrm{P}$ [6], the deletion of $\gamma \mathrm{G} 346-\mathrm{Q} 350$ [7], and $\gamma \mathrm{R} 375 \mathrm{~W}$ [5,8-14], $\gamma \mathrm{D} 316 \mathrm{~N}$ [15] and $\gamma \mathrm{G} 366 \mathrm{~S}$ [15]). $\gamma \mathrm{R} 375 \mathrm{~W}$ is designated as the Aguadilla mutation and has been identified in eight families from seven racial origins [5,8-14]. Variant protein-accumulating disease in hepatocytes and the induction of liver disease were originally reported for a homozygous deficiency of $\alpha 1$-antitrypsin (A1AT, G342K, the so-called Z-mutation) [16]. Moreover, the molecular mechanisms by which the A1AT Z-mutation causes hepatocyte injuries have been studied extensively and showed increased ER retention as a conformational disease, the activation of ER-specific stress responses, up-regulated mitochondrial autophagy, or mitochondrial injury and apoptosis [16-18]. Therefore, the A1AT Z-mutation is also designated as a hepatic ER storage disease [16,17]. 
We previously established $\gamma 375 \mathrm{~W}$ variant fibrinogen-producing Chinese hamster ovary $(\mathrm{CHO})$ cells and compared them with wild-type fibrinogen-producing cells for the synthesis of variant fibrinogen and morphological characteristics. We found that

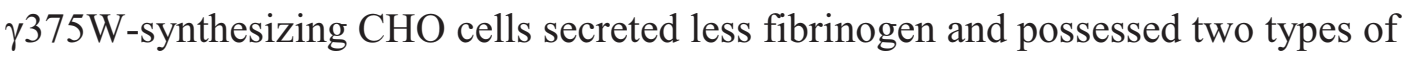
aberrant intracellular inclusion bodies, the large granular ('LG') and fibrous ('F') forms using immunofluorescence. We subsequently demonstrated that these inclusion bodies were derived from the ER using confocal laser scanning microscopy and transmission electron microscopy [19].

In the present study, to examine whether variant fibrinogen-producing cells and the immunofluorescence method may be utilized in the non-invasive screening of FSD-inducible variant fibrinogen, we established and observed five other $\mathrm{CHO}$ cell lines producing FSD-inducible variant fibrinogen and seven $\mathrm{CHO}$ cell lines producing FSD-non-inducible variant fibrinogen.

\section{Materials and methods}

Preparation of mutant expression vectors

The fibrinogen $\gamma$ chain expression vector $\mathrm{pMLP}-\gamma(\gamma \mathrm{N})[20]$ was altered by oligonucleotide-directed mutagenesis using the QuikChange II Site-Directed 
Mutagenesis Kit (Stratagene, La Jolla, CA, USA) and five mutagenesis primer pairs

(Supplement Table 1). The expression vectors for $\gamma 375 \mathrm{~W}, \gamma 313 \mathrm{~N}, \gamma 326 \mathrm{~A}, \gamma 326 \mathrm{~S}$, $\gamma 326 \mathrm{Y}, \gamma 336 \mathrm{I}, \gamma 341 \mathrm{D}$, and $\gamma 345 \mathrm{D}$ were previously mutated and described $[19,21,22]$.

Establishment of stable $\mathrm{CHO}$ cell lines producing variant fibrinogen

The resultant expression vectors, $\gamma 284 \mathrm{R}, \gamma 314 \mathrm{P}, \gamma 316 \mathrm{~N}, \gamma \Delta \mathrm{G} 346-\mathrm{Q} 350, \gamma 366 \mathrm{~S}$, $\gamma 375 \mathrm{~W}$, and $\gamma \mathrm{N}$ were co-transfected with the histidinol selection plasmid (pMSVhis) into $\mathrm{CHO}$ cells that expressed normal human fibrinogen $\mathrm{A} \alpha$ - and $\mathrm{B} \beta$-chains $(\mathrm{A} \alpha \mathrm{B} \beta-\mathrm{CHO}$ cells) as described previously [23] and the cell lines were designated as

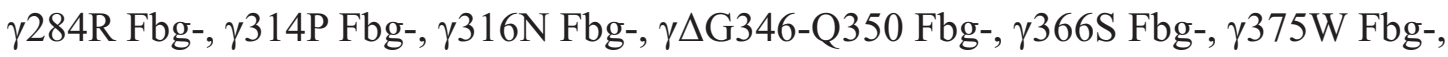
and $\gamma \mathrm{N} \mathrm{Fbg-CHO}$. Stable transfectants designated as the $\gamma 313 \mathrm{~N}$ Fbg-, $\gamma 326 \mathrm{~A} \mathrm{Fbg-}$ $\gamma 326 \mathrm{~S} \mathrm{Fbg-}, \gamma 326 \mathrm{Y} \mathrm{Fbg-}, \gamma 336 \mathrm{I} \mathrm{Fbg-}, \gamma 341 \mathrm{D}$ Fbg-, and $\gamma 345 \mathrm{D}$ Fbg-CHO cell lines were previously established and described $[21,22]$.

Moreover, the expression vectors coding $\gamma 314 \mathrm{P}, \gamma 316 \mathrm{~N}, \gamma \Delta \mathrm{G} 346-\mathrm{Q} 350, \gamma 375 \mathrm{~W}$, and $\gamma \mathrm{N}$ were transfected alone or co-transfected with the fibrinogen A $\alpha$-chain (pMLP-A $\alpha$ ) or $\mathrm{B} \beta$-chain expression vector ( $\mathrm{pMLP}-\mathrm{B} \beta$ ) and neomycin selection plasmid ( $\mathrm{pRSVneo)}$ as described above, and the established cell lines were designated as $\gamma 375 \mathrm{~W}-$, A $\alpha \gamma 375 \mathrm{~W}-$, and $\mathrm{B} \beta \gamma 375 \mathrm{~W}-\mathrm{CHO}$, respectively (representative for $\gamma 375 \mathrm{~W}$ ). 
Enzyme-linked immunosorbent assay and immunoblot analysis

Fibrinogen concentrations in the culture media or cell lysates of stable

fibrinogen-synthesizing $\mathrm{CHO}$ cells were assessed by an enzyme-linked immunosorbent assay (ELISA), as described previously [24].

Sodium dodecyl sulfate polyacrylamide gel electrophoresis (SDS-PAGE) under reducing conditions (10\% polyacrylamide gel) and an immunoblot analysis were performed as described previously [25]. Briefly, immunoblots were developed with a rabbit anti-human fibrinogen antibody (DAKO, Carpinteria, CA, USA), horseradish peroxidase conjugated-goat anti-rabbit IgG antibody (Medical and Biological Laboratories, Nagoya, Japan), and enhanced chemiluminescence (ECL) detection reagent (Amersham Pharmacia Biotech, Buckinghamshire, UK).

\section{Immunofluorescence staining}

In immunofluorescence microscopy, cells grown to $80 \%$ confluence on cover glasses in a $60-\mathrm{mm}$ culture dish were fixed with $4 \%$ paraformaldehyde and permeabilized with $0.2 \%$ Triton X-100 [19]. Variant fibrinogen-producing cells were incubated for $1 \mathrm{~h}$ with a 1:50 diluted fluorescein isothiocyanate (FITC)-labeled sheep polyclonal 
anti-fibrinogen antibody (Medical and Biological Laboratories) and then mounted with VECTASHIELD Hard-Set Mounting Medium (Funakoshi, Tokyo, Japan) [19]. Cells were observed using 0.8 - $\mu \mathrm{m}$-thick or $0.4-\mu \mathrm{m}$-thick optical sections by a confocal laser scanning microscope (LSM 510 META; Zeiss, Oberkochen, Germany) and scanned in 30 high-power fields (x 40 objective area). The percentages of aberrant inclusion body-positive cells (number of inclusion body-positive cells/total number of fibrinogen-synthesizing cells x 100) was evaluated by counting 1000 cells for $\gamma \mathrm{N}$ Fbg-cell lines and 500 cells for variant fibrinogen-synthesizing cell lines.

Transmission electron microscopy

In transmission electron microscopy, sample preparation was performed as described previously [19]. Specimens were observed on JEM -1230 (JEOL, Tokyo, Japan) and images were recorded at $\times 15,000$ with an accelerating voltage of $80 \mathrm{kV}$.

Transient transfection to $\mathrm{CHO}$ and $\mathrm{HuH}-7$ cells

One day before transfection, $\mathrm{A} \alpha \mathrm{B} \beta-\mathrm{CHO}$ cells and $\mathrm{HuH}-7$ cells (derived from human hepatoma and kindly provided by the RIKEN BRC through the National Bio-Resource Project of the MEXT, Japan) [26] were seeded on 6-well dishes until they 
reached $60 \%$ confluence. Expression vectors were transfected into $\mathrm{A} \alpha \mathrm{B} \beta-\mathrm{CHO}$ cells or HuH-7 cells using Lipofectamine 2000 (Invitrogen, Carlsbad, CA, USA), according to the manufacturer's instructions. Immunofluorescence staining was performed 4 days after transfection, as described above.

\section{Statistical analysis}

The significance of differences in fibrinogen concentrations between wild-type and variant fibrinogen-producing cells was examined using a one-way ANOVA (analysis of variance) and Turkey-Kramer tests. The significance of differences in aberrant inclusion bodies between FSD- and FSD-non-inducible variant fibrinogens was assessed by the non-parametric Mann-Whitney U-test. A difference was considered significant when the $p$ value was $<0.05$.

\section{Results}

Synthesis and secretion of recombinant variant fibrinogens in $\mathrm{CHO}$ cells.

Normal and variant fibrinogen-inducible FSD were expressed in $\mathrm{CHO}$ cells and 9 to 12 fibrinogen-synthesizing cell lines each were selected as described in the Materials and Methods. Fibrinogen concentrations in culture media and cell lysates were 
measured by ELISA. The results obtained are shown in Fig. 1A-Fig. 1C. In $\gamma \mathrm{N}$ Fbg-CHO cells, the concentrations of fibrinogen were $0.83 \pm 0.20 \mu \mathrm{g} / \mathrm{mL}$ (mean $\pm \mathrm{SD}, \mathrm{n}$ =9) for culture media and $1.15 \pm 0.38 \mu \mathrm{g} / \mathrm{mL}$ for cell lysates, resulting in a culture medium to cell lysate ratio of $0.77 \pm 0.22$. Apart from $\gamma 316 \mathrm{~N} \mathrm{Fbg-CHO}$ cells, fibrinogen concentrations in the culture medium of the variant fibrinogen-synthesizing cell lines were significantly lower than that of $\gamma \mathrm{N} \mathrm{Fbg-CHO}$ cells (Fig. 1A). On the other hand, fibrinogen concentrations in all variant cell lysates were higher than that in $\gamma \mathrm{N}$ Fbg-CHO cells (Fig. 1B). All variant medium/cell lysate fibrinogen ratios were markedly lower than that of $\gamma \mathrm{N}$ Fbg-CHO cells: $\gamma 284 \mathrm{R} ; 0.05 \pm 0.01, \gamma 314 \mathrm{P} ; 0.08 \pm 0.04$, $\gamma 316 \mathrm{~N} ; 0.26 \pm 0.05, \gamma \Delta 346-350 ; 0.08 \pm 0.05, \gamma 366 \mathrm{~S} ; 0.03 \pm 0.02, \gamma 375 \mathrm{~W} ; 0.09 \pm 0.02$ (Fig. 1C).

Fibrinogen staining for established stable variant $\mathrm{CHO}$ cells.

In order to investigate whether the ' $L G$ ' and ' $F$ ' forms of aberrant intracellular inclusion bodies exist in $\mathrm{CHO}$ cells, direct immunofluorescence staining was performed as described in the Materials and Methods (Fig. 1D, Supplement Figure 1). Original $\mathrm{CHO}$ cells were used as a negative control and $\gamma \mathrm{N} \mathrm{Fbg-CHO} \mathrm{cells} \mathrm{as} \mathrm{a} \mathrm{normal} \mathrm{control.}$ In fibrinogen variant-inducible FSD, $\gamma 314 \mathrm{P} \mathrm{Fbg-} \mathrm{and} \gamma \Delta \mathrm{G} 346-\mathrm{Q} 350 \mathrm{Fbg}-\mathrm{CHO}$ cells 
showed aberrant intracellular inclusion bodies, similar to $\gamma 375 \mathrm{~W}$ Fbg-CHO cells [19].

Since characteristic long and straight needle-like inclusion bodies were observed in $\gamma 316 \mathrm{~N}$ Fbg-CHO cells (Fig. 1D), we classified these as the ' $F$ ' form. Briefly, on day 4 after the subculture, the proportion of each staining pattern ('LG' and 'F', Supplement Figure 1) was as follows: $\gamma 314 \mathrm{P}$ Fbg-CHO cells; $27.2 \%$ and $37.3 \%, \gamma 316 \mathrm{~N} \mathrm{Fbg-CHO}$ cells; $8.4 \%$ and $72.1 \%, \gamma \Delta 346-350$ Fbg-CHO cells; $53.7 \%$ and $12.3 \%, \gamma 375 \mathrm{~W}$ Fbg-CHO cells; $50.5 \%$ and $40.0 \%$, respectively (Fig. 1D). On the other hand, $\gamma 284 \mathrm{R}$ Fbg-CHO cells (Fig. 1D) showed $8.4 \%$ of the ' $L G$ ' form and $0 \%$ of the ' $F$ ' form, while $\gamma 366 \mathrm{~S}$ Fbg-CHO cells showed $17.7 \%$ of the ' $L G$ ' form and $0 \%$ of the ' $F$ ' form (Fig. 1D). We immunofluorescently stained two other clones for $\gamma 284 \mathrm{R}$ and $\gamma 366 \mathrm{~S}$ Fbg-CHO cells, but did not observe the 'F' form (Table 1).

In the hypofibrinogenemic variants reported to not induce FSD [27-31], $\gamma 326 \mathrm{Y} \mathrm{Fbg-,}$ $\gamma 336$ I Fbg-, and $\gamma 341 \mathrm{D}$ Fbg-CHO cells had less than $1.0 \%$ of the 'LG' form and $0 \%$ of the 'F' form, whereas $\gamma 313 \mathrm{~N} \mathrm{Fbg-,} \gamma 326 \mathrm{~A} \mathrm{Fbg-}$, $\gamma 326 \mathrm{~S}$ Fbg-, and $\gamma 345 \mathrm{D}$ Fbg-CHO cells had more than $8 \%$ of the ' $L G$ ' form: $14.3 \%, 13.1 \%, 23.0 \%$, and $8.6 \%$, respectively, and $0 \%$ of the ' $\mathrm{F}$ ' form, (Fig. 2). We only observed the ' $\mathrm{LG}$ ' form for variant fibrinogen-synthesizing CHO cells not inducing FSD. 
Transient transfection of variant $\gamma$-chains into $\mathrm{CHO}$ cells or HuH-7 cells

On day 4 after transfection, the proportions of the ' $L G$ ' and ' $F$ ' forms of inclusion bodies were as follows: $\gamma 314 \mathrm{P} \mathrm{Fbg-,} \gamma 316 \mathrm{~N} \mathrm{Fbg-}, \gamma \Delta 346-350$ Fbg-, and $\gamma 375 \mathrm{~W}$ Fbg-CHO cells had $21.8 \%$ and $5.3 \%, 5.4 \%$ and $35.6 \%, 25.5 \%$ and $3.2 \%, 15.5 \%$ and 22.7\%, respectively (Fig. 3A), and all values were lower than those obtained from stable transfectants. On the other hand, in $\gamma 284 \mathrm{R}$ Fbg-CHO cells, the ' $\mathrm{LG}$ ' form was 9.4\% and the ' $\mathrm{F}$ ' form was $4.9 \%$. In $\gamma 366 \mathrm{~S} \mathrm{Fbg-CHO}$ cells, the ' $\mathrm{LG}$ ' form was $5.6 \%$ and the ' $F$ ' form was $4.6 \%$ (Fig. 3A). We transfected transiently the variant $\gamma$-chain three times and the ' $\mathrm{F}$ ' form was observed at $3.4 \pm 1.8 \%$ in $\gamma 284 \mathrm{R}$ Fbg-CHO cells and at 3.1 $\pm 1.4 \%$ in $\gamma 366 \mathrm{~S}$ Fbg-CHO cells (Table 1).

Since we speculated that the lower percentage of the 'F' form in $\gamma 284 \mathrm{R}$ Fbg- and $\gamma 366 \mathrm{~S} \mathrm{Fbg-CHO}$ cells may be caused by $\mathrm{CHO}$ cells that were non-hepatic and non-human cells, we performed the transient transfection of the variant $\gamma$-chain into the human hepatocyte cell line, HuH-7. Normal fibrinogen-producing cells, $\gamma \mathrm{N} \mathrm{Fbg-HuH-7}$ cells, were stained in a similar pattern to original HuH-7 cells, $\gamma 284 \mathrm{R} \mathrm{Fbg-,} \mathrm{\gamma 314P} \mathrm{Fbg-,}$ $\gamma 316 \mathrm{~N}$ Fbg-, $\gamma \Delta \mathrm{G} 346-\mathrm{Q} 350$ Fbg-, $\gamma 366 \mathrm{~S}$ Fbg-, and $\gamma 375 \mathrm{~W}$ Fbg-HuH-7 cells that stained positive for the 'LG' and ' $\mathrm{F}$ ' forms, similar to transiently transfected $\mathrm{CHO}$ cell lines (Fig. 3B). We transfected transiently the variant $\gamma$-chain three times and the ' $F$ ' form 
was observed at $1.4 \pm 0.6 \%$ in $\gamma 284 \mathrm{R} \mathrm{Fbg-HuH-7} \mathrm{cells} \mathrm{and} \mathrm{at} 3.2 \pm 0.5 \%$ in $\gamma 366 \mathrm{~S}$

Fbg-HuH-7 cells (Table 1). Furthermore, we performed immunofluorescence staining for transient transfectants whose variant fibrinogen resulted in hypofibrinogenemia, but

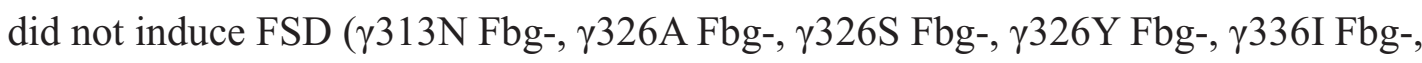
$\gamma 341 \mathrm{D}$ Fbg-, and $\gamma 345 \mathrm{D}$ Fbg-HuH-7 cells). The staining patterns and positive percentages ('LG' form: $0.2 \sim 7.0 \%$ and ' $\mathrm{F}$ ' form: $0 \%$ ) of aberrant inclusion bodies were similar to those obtained from transiently transfected $\mathrm{CHO}$ cell lines ('LG' form: 0.4 8.1\% and ' $\mathrm{F}$ ' form: $0 \%$ ) (Table 2 and images not shown).

The percentages of the ' $\mathrm{LG}$ ' and ' $\mathrm{F}$ ' forms in $\mathrm{CHO}$ and $\mathrm{HuH}-7$ cells stained by a fibrinogen antibody were summarized in Figure 4. Medians and interquartile ranges depending on distributions were shown using a Box and Whisker plot. The ' $F$ ' form was observed in all six FSD-inducible variants of transiently transfected $\mathrm{CHO}$ cells and HuH-7 cells, but was absent in two ( $\gamma 284 \mathrm{R}$ Fbg and $\gamma 366 \mathrm{~S}$ Fbg) out of six variants of stably transfected CHO cells. The 'F' form was not observed in FSD-non-inducible variants of stably or transiently transfected $\mathrm{CHO}$ cells or transiently transfected $\mathrm{HuH}-7$ cells. Furthermore, the non-parametric Mann-Whitney U-test revealed that the percentage of the 'LG' form was significantly higher in cells with FSD-inducible variants than in those with FSD-non-inducible variants. 


\section{Transmission electron microscopy}

In order to compare the aberrant structure of the ER in stably transfected $\gamma 375 \mathrm{~W}$ Fbg-CHO cells, we performed transmission electron microscopic observations on five other stably transfected FSD-inducible variant cell lines of CHO cells. Images are shown in Figure 5. The 'LG' form observed by immunofluorescence showed enlarged vacuoles in the ER, the outer surface of which had ribosomes attached, while those in $\gamma 284 \mathrm{R}$ Fbg- (Fig. 5B) and $\gamma 366 \mathrm{~S} \mathrm{Fbg-CHO}$ cell lines (Fig. 5C) were similar to those observed in $\gamma 375 \mathrm{~W}$ Fbg-CHO cells (Fig. 5D). Furthermore, the ' $F$ ' form showed an expanded ER. The outer surface also had ribosomes attached and the lumen was filled with regularly structured fibular materials, while those in $\gamma 314$ P Fbg- (Fig. 5E) and $\gamma \Delta$ G346-Q350 Fbg-CHO cells (Fig. 5G) were similar to those observed in $\gamma 375 \mathrm{~W}$ Fbg-CHO cells (Fig. 5H). However, the expanded ER in $\gamma 316 \mathrm{~N} \mathrm{Fbg-CHO} \mathrm{cells} \mathrm{(Fig.}$ 5F) was markedly wider than that in $\gamma 375 \mathrm{~W}$ Fbg-CHO cells (Fig. 5H) and the lumen was packed with a larger number of regularly structured fibular materials (Fig. 5H). These figures corresponded to a fingerprint-like pattern, as shown in the hepatocytic inclusion bodies of FSD patients by transmission electron microscopy [4,6-15]. 
Function of the variant $\gamma$-chain, $\gamma 314 P, \gamma 316 N, \gamma \Delta G 346-Q 350$, and $\gamma 375 \mathrm{~W}$ in the formation of the aberrant ' $F$ ' form

In order to clarify whether the aberrant ' $\mathrm{F}$ ' form in $\gamma 314 \mathrm{P} \mathrm{Fbg-,} \gamma 316 \mathrm{~N} \mathrm{Fbg-,}$ $\gamma \Delta \mathrm{G} 346-\mathrm{Q} 350 \mathrm{Fbg}-$, and $\gamma 375 \mathrm{~W}$ Fbg-CHO cells is formed by the sole transfection of the variant $\gamma$-chain vector, we established variant $\mathrm{CHO}$ cell lines that only expressed the variant $\gamma$-chain (for example, designated as $\gamma 375 \mathrm{~W}$ CHO cells), normal fibrinogen A $\alpha$ plus the variant $\gamma$-chain (for example, designated as A $\alpha \gamma 375 \mathrm{~W}$ CHO cells), or B $\beta$ plus the variant $\gamma$-chain (for example, designated as $\mathrm{B} \beta \gamma 375 \mathrm{~W} \mathrm{CHO}$ cells), and compared them with $\gamma 375 \mathrm{~W}$ Fbg-CHO cells. SDS-PAGE and immunoblot analyses of cell lysates were performed under reducing conditions to confirm the synthesis of each peptide chain. Not only the $\gamma$-chain, but also the $A \alpha$ - or $B \beta$-chain was observed in established CHO cell lines (Fig. 6A). Although $\gamma 375 \mathrm{~W}$ Fbg-CHO cells showed a large number of aberrant inclusion bodies including the ' $\mathrm{F}$ ' form, not only $\gamma 375 \mathrm{~W} \mathrm{CHO}$ cells, but also A $\alpha \gamma 375 \mathrm{~W}$ CHO cells and $\mathrm{B} \beta \gamma 375 \mathrm{~W}$ CHO cells had no aberrant intracellular inclusion bodies of the 'LG' or ' $F$ ' form (Fig. 6B). The same results were obtained for three other variant $\gamma$-chain vectors: $\gamma 314 \mathrm{P}, \gamma 316 \mathrm{~N}$, and $\gamma \Delta \mathrm{G} 346-\mathrm{Q} 350$ (data not shown).

\section{Discussion}


The heterozygous variant fibrinogen, $\gamma \mathrm{R} 375 \mathrm{~W}$ is known as fibrinogen Aguadilla and induces hypofibrinogenemia and FSD [5,8-14]. We previously established recombinant $\gamma 375 \mathrm{~W}$ stably producing $\mathrm{CHO}$ cells and observed the aberrant intracellular inclusion bodies, the 'LG' and ' $F$ ' forms, using an immunofluorescence method. Both inclusion bodies were identified as the ER by confocal microscopy and transmission electron microscopy [19]. Based on these results, we investigated whether variant fibrinogen-producing cells and the immunofluorescence method may be utilized in the screening of FSD-inducible variant fibrinogen.

In the present study, we established five other stably or transiently recombinant variant fibrinogens inducing FSD: $\gamma 284 \mathrm{R}$ [4,5], $\gamma 314 \mathrm{P}[6], \gamma \Delta \mathrm{G} 346-\mathrm{Q} 350$ [7], $\gamma \mathrm{D} 316 \mathrm{~N}$ [15], and $\gamma \mathrm{G} 366 \mathrm{~S}$ [15], and seven recombinant variant fibrinogens inducing

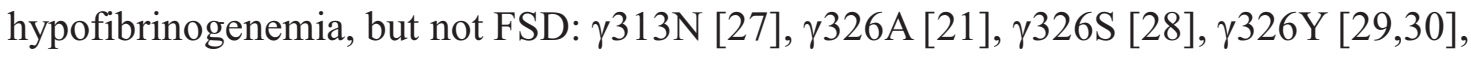
$\gamma 336 \mathrm{I}[30], \gamma 341 \mathrm{D}$ [31], and $\gamma 345 \mathrm{D}$ [30]. In the former FSD-inducible variant cell lines of $\mathrm{CHO}$ cells, all transient transfectants were positive for the ' $\mathrm{LG}$ ' and ' $\mathrm{F}$ ' forms. However, in the latter FSD-non-inducible variant cell lines of CHO cells, all transient transfectants were positive for the 'LG' form only. Therefore, the results obtained from immunofluorescence staining led us to the conclusion that the detection of the ' $F$ ' form in variant fibrinogen-synthesizing $\mathrm{CHO}$ cells may be specific to the FSD-inducible type 
of the hypofibrinogenemic variant. These results indicate that establishing variant fibrinogen transiently synthesizing $\mathrm{CHO}$ cells followed by immunostaining using a fibrinogen antibody has potential as a non-invasive screening method for the FSD-inducible type of the hypofibrinogenemic variant. However, difficulties are associated with explaining the difference between positivity for the ' $F$ ' form in transient transfectants of $\mathrm{CHO}$ cells and negativity in stable transfectants of $\mathrm{CHO}$ cells. Namely, the ' $\mathrm{F}$ ' form was not detected in stable transfectants for $\gamma 284 \mathrm{R} \mathrm{Fbg}$ - and $\gamma 366 \mathrm{~S}$ Fbg-CHO cells, whereas we observed low percentages of the ' $\mathrm{F}$ ' form in transient transfectants for $\gamma 284 \mathrm{R} \mathrm{Fbg-} \mathrm{and} \gamma 366 \mathrm{~S}$ Fbg-CHO cells.

It is of interest that human hepatocytes cell lines that natively produce fibrinogen, HuH-7 cells, are used as host cells for transfection. Since most FSD patients are heterozygotes for fibrinogen gene mutations, we hypothesize that the positive percentages of the 'LG' and/or ' $F$ ' forms for variant fibrinogen-synthesizing $\mathrm{HuH}-7$ cells may be higher than those for variant fibrinogen-synthesizing xenogeneic and non-native cell lines, $\mathrm{CHO}$ cells. Therefore, we transiently transfected expression vectors into $\mathrm{HuH}-7$ cells. Although these $\mathrm{HuH}-7$ cells may produce homodimers of wild-type or variant fibrinogens and heterodimers of wild-type and variant fibrinogens and be analogous to the hepatocytes of heterozygous patients, the positive percentages 
of the 'LG' and/or 'F' forms of HuH-7 cells were similar to those of CHO cells. Since $\mathrm{CHO}$ cells grow faster than $\mathrm{HuH}-7$ cells and are easier to maintain, we selected $\mathrm{CHO}$ cells in the screening of FSD-inducible variant fibrinogen.

The percentages of the ' $\mathrm{F}$ ' form in transient transfectants were divided into two groups, namely, higher $(22.7 \%$ and $35.6 \%) ; \gamma 375 \mathrm{~W}$ and $\gamma 316 \mathrm{~N}$, and lower $(4.9 \%, 5.3 \%$, $3.2 \%$, and $4.6 \%) ; \gamma 284 \mathrm{R}, \gamma 314 \mathrm{P}, \gamma \Delta \mathrm{G} 346-\mathrm{Q} 350$, and $\gamma 366 \mathrm{~S}$. These percentages of the ' $\mathrm{F}$ ' form did not correlate with the synthesis, secretion, or medium/cell lysate fibrinogen ratios of variant fibrinogen stably expressed in $\mathrm{CHO}$ cells. Furthermore, the higher percentage of ' $\mathrm{F}$ ' form-positive cells may not be related to liver functions or diseases or the age of onset [13]. These results suggest that genetic fibrinogen mutation carriers exhibit extreme variability in the severity of liver injury [13]. This variability indicates that the development of FSD is dependent not only on genetic fibrinogen mutations, but also additional environmental or genetic factors [13]. However, our procedure is useful for the screening of the FSD-inducible hypofibrinogenemic variant. On the other hand, the presence of the 'LG' form is difficult to interpret. Namely, the ' $L G$ ' forms from the FSD-inducible hypofibrinogenemic variant and FSD-non-inducible hypofibrinogenemic variant are the same or different, while that from the FSD-inducible hypofibrinogenemic variant may or may not transition to the ' $F$ ' form. Under our experimental conditions, 
double-positive $\mathrm{CHO}$ or $\mathrm{HuH}-7$ cells with the ' $\mathrm{LG}$ ' and ' $\mathrm{F}$ ' forms were absent. We speculate that the presence of the 'LG' form reflects the reduced secretion of fibrinogen in transfected cells.

The molecular mechanisms by which variant fibrinogen induces FSD have not yet been elucidated; however, some hypotheses have been proposed; 1) mutant fibrinogen avoids the quality control ER-associated degradation pathway; namely, FSD is one of the hepatic ER storage diseases demonstrated with the A1AT Z-mutation [16,17], 2) mutant fibrinogen avoids the autophagy degradation pathway [16,18], and 3) the fibrin-like conversion of fibrinogen occurs inside the ER. Electron microscopic examinations of biopsy samples of FSD livers revealed unique images, the so-called fingerprint pattern, namely, a regular aggregation pattern of fibrinogen [4-15]. Furthermore, we found that the ER lumen was filled with regularly structured fibular materials in $\gamma 314 \mathrm{P}, \gamma 316 \mathrm{~N}, \gamma \Delta \mathrm{G} 346-\mathrm{Q} 350$, and $\gamma 375 \mathrm{~W}$ Fbg-CHO cells and these appeared to have a fingerprint-like pattern, as shown in the hepatocytes of FSD patients. In order to clarify the third hypothesis, we analyzed the mechanisms underlying the formation of 'LG' and ' $\mathrm{F}$ ' form inclusion bodies using $\gamma 314 \mathrm{P}, \gamma 316 \mathrm{~N}, \gamma \Delta \mathrm{G} 346-\mathrm{Q} 350$, and $\gamma 375 \mathrm{~W}$ vectors with several combinations of normal $\mathrm{A} \alpha$ - and/or $\mathrm{B} \beta$-chain expression vectors. The results obtained revealed the aberrant intracellular inclusion 
bodies were formed solitary by the assembly of variant $\gamma$-chains into normal A $\alpha$ - and $\mathrm{B} \beta$-chains. In other words, the hexameric fibrinogen structure was crucial for the formation of the 'LG' and 'F' forms of inclusion bodies. However, our results did not clarify whether the fibrin-like conversion of fibrinogen occurred inside the ER.

Histological liver sections from A1AT Z-mutation [16] and FSD patients [4-15] show intracytoplasmic round eosinophilic inclusions surrounded by a clear halo; however, the former inclusions are more clearly visualized with the periodic acid-Schiff stain following a pretreatment with diastase (PASD), while the latter inclusions are negative on PASD staining. Therefore, immunostaining using specific antibodies is needed in order to differentiate the liver disorders caused by the A1AT Z-mutation and fibrinogen mutation. In addition, our preliminary experiment for $\mathrm{CHO}$ cells transfected with the plasmid containing cDNA with the A1AT Z-mutation only revealed the 'LG' form, namely, none of the ' $F$ ' forms (data not shown). Accordingly, we speculate that the molecular mechanisms underlying the formation of inclusions and accumulation of variant proteins in hepatocytes may differ between the A1AT Z-mutation and fibrinogen mutation.

In conclusion, variant fibrinogen-producing cells and immunofluorescence staining are applicable as a non-invasive and useful procedure for screening for the presence or 
absence of principal risk factors for FSD-inducible variant fibrinogen before its onset.

$\mathrm{CHO}$ cell lines transiently synthesizing variant fibrinogen showed the ' $\mathrm{F}$ ' form specific for FSD more than stably synthesizing $\mathrm{CHO}$ cell lines. On the other hand, $\mathrm{CHO}$ cell lines stably synthesizing variant fibrinogen may be a useful tool for analyses of the molecular mechanisms responsible for the accumulation of fibrinogen and formation of the 'LG' and/or ' $F$ ' forms of inclusion bodies.

\section{Authorship}

Study concept and design: N Okumura, S Arai. M Sugano, T Honda. Experiment: S Arai, N Ogiwara, S Mukai, Y Takezawa. Data analysis and figure preparation: N Okumura, S Arai, M Sugano, T Honda. Drafting of the manuscript: N Okumura, S Arai. Critical revision of the manuscript: N Okumura, S Arai, M Sugano, T Honda.

\section{Conflicts of Interest}

None of the authors have any conflicts of interest with regards to this work.

\section{Acknowledgments}

This work was supported by JSPS KAKENHI Grant Number 26460672 (N Okumura). 


\section{References}

[1] Mosesson MW. Fibrinogen and fibrin structure and functions. J Thromb Haemost. 2005;3:1894-904.

[2] Lord ST. Fibrinogen and fibrin: scaffold proteins in hemostasis. Curr Opin Hematol. 2007;14:236-41.

[3] De Moerloose P, Neerman-Arbez M, Congenital fibrinogen disorders. Semin Thromb Hemost. 2009;35:56-66.

[4] Brennan SO, Wyatt J, Medicina D, Callea F, George PM, Fibrinogen Brescia: Hepatic endoplasmic reticulum storage and hypofibrinogenemia because of a $\gamma 284$ Gly->Arg mutation. Am J Pathol. 2000;157:189-96.

[5] Puls F, Goldschmidt I, Bantel H, Agne C, Bröcker V, Dämmrich M, et al. Autophagy-enhancing drug carbamazepine diminishes hepatocellular death in fibrinogen storage disease. J Hepatol. 2013;59:626-30.

[6] Brennan SO, Davis RL, Conard K, Savo A, Furuya KN. Novel fibrinogen mutation $\gamma 314 \mathrm{Thr} \rightarrow$ Pro (fibrinogen AI duPont) associated with hepatic fibrinogen storage disease and hypofibrinogenaemia. Liver Int. 2010;30:1541-7. 
[7] Dib N, Quelin F, Ternisien C, Hanss M, Michalak S, De Mazancourt P, et al. Fibrinogen Angers with a new deletion ( $\gamma$ GVYYQ 346-350) causes hypofibrinogenemia with hepatic storage. J Thromb Haemost. 2007;5:1999-2005.

[8] Brennan SO, Maghzal G, Shneider BL, Gordon R, Magid MS, George PM. Novel fibrinogen $\gamma 375$ Arg--> Trp mutation (fibrinogen Aguadilla) causes hepatic endoplasmic reticulum storage and hypofibrinogenemia. Hepatology 2002;36:652-8.

[9] Francalanci P, Santorelli FM, Talini I, Boldrini R, Devito R, Camassei FD, et al. Severe liver disease in early childhood due to fibrinogen storage and de novo gamma375Arg->Trp gene mutation. J Pediatr. 2006;148:396-8.

[10] Rubbia-Brandt L, Neerman-Arbez M, Rougemont A-L, Malé P-J, Spahr L. Fibrinogen gamma375 Arg-> Trp mutation (fibrinogen Aguadilla) causes hereditary hypofibrinogenemia, hepatic endoplasmic reticulum storage disease and cirrhosis. Am J Surg Pathol. 2006;30:906-11.

[11] Sogo T, Nagasaka H, Komatsu H, Inui A, Miida T, Callea F, et al. Fibrinogen storage disease caused by Aguadilla mutation presenting with hypobeta-lipoproteinemia and considerable liver disease. J Pediatr Gastroenterol Nutr. 2009;49:133-6. 
[12] Al-Hussaini A, Altalhi A, El Hag I, Al-Hussaini H, Francalanci P, Giovannoni I, et al. Hepatic fibrinogen storage disease due to the fibrinogen $\gamma 375 \operatorname{Arg} \rightarrow \operatorname{Trp}$ mutation "fibrinogen Aguadilla" is present in Arabs. Saudi J Gastroenterol. 2014;20:255-61.

[13] Casini A, Sokollik C, Lukowski SW, Lurz E, Rieubland C, de Moerloose P, et al. Hypofibrinogenemia and liver disease: a new case of Aguadilla fibrinogen and review of the literature. Haemophilia 2015;21:820-7.

[14] Sari S, Yilmaz G, Gonul II, Dalgic B, Akyol G, Giovannoni I, et al. Fibrinogen storage disease and cirrhosis associated with hypobetalipoproteinemia owing to fibrinogen Aguadilla in a Turkish child. Liver Int. 2015;35:2501-5.

[15] Asselta R, Robusto M, Braidotti P, Peyvandi F, Nastasio S, D’Antiga L, et al. Hepatic fibrinogen storage disease: identification of two novel mutations (p.Asp316Asn, fibrinogen Pisa and p.Gly366Ser, fibrinogen Beograd) impacting on fibrinogen $\gamma$-module. J Thromb Haemost. 2015;13:1459-67.

[16] Carrell RW, Lomas DA. Alpha 1-antitrypsin deficiency - A model for conformational diseases. N Engl J Med. 2002;346:45-53. 
[17] Lawless MW, Greene CM, Mulgrew A, Taggart CC, O’Neill SJ, McElvaney NG. Activation of endoplasmic reticulum-specific stress responses associated with the conformational disease Z alpha 1-antitrypsin deficiency. J Immunol. 2004;17:5722_ 6.

[18] Teckman JH, An J-K, Blomenkamp K, Schmidt B, Perlmutter D. Mitochondrial autophagy and injury in the liver in alpha 1-antitrypsin deficiency. Am J Physiol Gastrointest Liver Physiol. 2004;286:G851-62.

[19] Kobayashi T, Arai S, Ogiwara N, Takezawa Y, Nanya M, Terasawa F, et al. $\gamma 375 \mathrm{~W}$ fibrinogen-synthesizing $\mathrm{CHO}$ cells indicate the accumulation of variant fibrinogen within endoplasmic reticulum. Thromb Res. 2014;133:101-7.

[20] Rooney MM, Parise LV, Lord ST. Dissecting clot retraction and platelet aggregation: Clot retraction does not require an intact fibrinogen chain $\mathrm{C}$ terminus. $\mathrm{J}$ Biol Chem. 1996;271:8553-5.

[21] Haneishi A, Terasawa F, Fujihara N, Yamauchi K, Okumura N, Katsuyama T. Recombinant variant fibrinogens substituted at residues $\gamma 326 \mathrm{Cys}$ and $\gamma 339 \mathrm{Cys}$ demonstrated markedly impaired secretion of assembled fibrinogen. Thromb Res. $2009 ; 124: 368-72$. 
[22] Terasawa F, Kamijyo Y, Fujihara N, Okumura N. Assembly and secretion of mutant fibrinogens with variant gamma-chain $C$ terminal region $(\gamma 313-\gamma 345)$.

Rinsho Byori. 2010;58:772-8. (In Japanese)

[23] Okumura N, Gorkun OV, Lord ST. Severely impaired polymerization of recombinant fibrinogen $\gamma 364$ Asp -> His, the substitution discovered in a heterozygous individual. J Biol Chem. 1997;272:29596-601.

[24] Terasawa F, Okumura N, Kitano K, Hayashida N, Shimosaka M, Okazaki M, et al. Hypofibrinogenemia associated with a heterozygous missense mutation $\gamma 153 \mathrm{Cys}$ to Arg (Matsumoto IV): in vitro expression demonstrates defective secretion of the variant fibrinogen. Blood 1999;94:4122-31.

[25] Okumura N, Terasawa F, Tanaka H, Hirota M, Ota H, Kitano K, et al. Analysis of fibrinogen $\gamma$-chain truncations shows the C-terminus, particularly $\gamma$ Ile 387 , is essential for assembly and secretion of this multichain protein. Blood 2002;99:3654-60.

[26] Nakabayashi H, Taketa K, Miyano K, Yamane T, Sato J. Growth of human hepatoma cell lines with differentiated functions in chemically defined medium. Cancer Res. 1982;42:3858-63. 
[27] Meyer M, Bergmann F, Brennan SO. Novel fibrinogen mutation ( $\gamma 313$ Ser->Asn) associated with hypofibrinogenemia in two unrelated families. Blood Coagul Fibrinolysis. 2006;17:63-7.

[28] Guglielmone HA, Sanchez MC, Abate Daga D, Bocco JL. A new heterozygous mutation in gamma fibrinogen gene leading to $326 \mathrm{Cys}->$ Ser substitution in fibrinogen Córdoba is associated with defective polymerization and familial hypodysfibrinogenemia. J Thromb Haemost. 2004;2:352-4.

[29] Dear A, Brennan SO, George PM. Familial hypodysfibrinogenaemia associated with second occurrence of $\gamma 326$ Cys-> Tyr mutation. Thromb Haemost. 2005;93:612-3.

[30] Meyer M, Franke K, Richter W, Steiniger F, Seyfert UT, Schenk J, et al. New molecular defects in the gamma subdomain of fibrinogen D-domain in four cases of (hypo)dysfibrinogenemia: fibrinogen variants Hannover VI, Homburg VII, Stuttgart and Suhl. Thromb Haemost. 2003;89:637-46.

[31] Song KS, Park NJ, Choi JR, Doh HJ, Chung KH. Fibrinogen Seoul (FGG Ala341Asp): a novel mutation associated with hypodysfibrinogenemia. Clin Appl Thromb Hemost. 2006;12:338-43. 


\section{Figure legends}

Figure 1. Synthesis and secretion of variant fibrinogens and immunofluorescence staining for stable FSD-inducing variant fibrinogen-producing $\mathrm{CHO}$ cell lines.

The concentrations of fibrinogen in culture media (A) and cell lysates (B) were measured by ELISA. The ratio of fibrinogen concentrations in culture media to those in cell lysates is shown in panel $\mathrm{C}$. The mean value was presented with standard deviations indicated by error bars. Concentrations were assessed for between 9 and 12 isolates of CHO cell lines expressing: $\gamma \mathrm{N}$; normal control (wild-type) cells $(\mathrm{n}=9), \gamma 284 \mathrm{R} ; \gamma 284 \mathrm{R}$ Fbg-CHO cells $(n=10), \gamma 314 \mathrm{P} ; \gamma 314 \mathrm{P}$ Fbg-CHO cells $(\mathrm{n}=10), \gamma 316 \mathrm{~N} ; \gamma 316 \mathrm{~N}$ Fbg-CHO cells $(\mathrm{n}=10), \gamma \Delta ; \gamma \Delta \mathrm{G} 346-\mathrm{Q} 350$ Fbg-CHO cells $(\mathrm{n}=10), \gamma 366 \mathrm{~S} ; \gamma 366 \mathrm{~S}$ Fbg-CHO cells $(n=10), \gamma 375 \mathrm{~W} ; \gamma 375 \mathrm{~W}$ Fbg-CHO cells $(\mathrm{n}=12)$. Significantly different from $\gamma \mathrm{N}\left({ }^{*} p<0.05, * * p<0.01\right)$.

Fixed and permeabilized CHO cell lines were stained with a FITC-labeled anti-fibrinogen antibody (D). Original $\mathrm{CHO}$ cells as a negative control, $\gamma \mathrm{N}$ Fbg-CHO cells $(\gamma \mathrm{N})$ as a normal control, $\gamma 284 \mathrm{R}$ Fbg- $(\gamma 284 \mathrm{R}), \gamma 314 \mathrm{P}$ Fbg- $(\gamma 314 \mathrm{P}), \gamma 316 \mathrm{~N} \mathrm{Fbg-}$ $(\gamma 316 \mathrm{~N}), \gamma \Delta \mathrm{G} 346-\mathrm{Q} 350$ Fbg- $(\gamma \Delta), \gamma 366 \mathrm{~S}$ Fbg- $(\gamma 366 \mathrm{~S})$, and $\gamma 375 \mathrm{~W}$ Fbg-CHO cells $(\gamma 375 \mathrm{~W})$ were shown. LG: scattered large granular form, F: fibrous form. Scale bar $=20$ $\mu \mathrm{m}$. The percentages of the 'LG', 'F', and normal forms were indicated under the photo. 
Figure 2. Immunofluorescence staining for stable FSD-non-inducing variant fibrinogen-synthesizing CHO cell lines.

Fixed and permeabilized CHO cell lines were stained with a FITC-labeled anti-fibrinogen antibody. $\gamma \mathrm{N} \mathrm{Fbg-CHO}$ cells $(\gamma \mathrm{N})$ as a normal control, $\gamma 313 \mathrm{~N}$ Fbg$(\gamma 313 \mathrm{~N}), \gamma 326 \mathrm{~A} \mathrm{Fbg}-(\gamma 326 \mathrm{~A}), \gamma 326 \mathrm{~S} \mathrm{Fbg}-(\gamma 326 \mathrm{~S}), \gamma 326 \mathrm{Y} \mathrm{Fbg}-(\gamma 326 \mathrm{Y}), \gamma 336 \mathrm{I} \mathrm{Fbg}-$ $(\gamma 336 \mathrm{I}), \gamma 341 \mathrm{D}$ Fbg- $(\gamma 341 \mathrm{D})$, and $\gamma 345 \mathrm{D}$ Fbg-CHO cells $(\gamma 345 \mathrm{D})$ were shown. LG: scattered large granular form. Scale bar $=20 \mu \mathrm{m}$. The percentages of the 'LG', 'F', and normal forms were indicated under the photo.

Figure 3. Immunofluorescence staining for transient variant $\mathrm{CHO}$ cell lines and

\section{HuH-7 cell lines.}

Transient variant fibrinogen-synthesizing $\mathrm{CHO}$ cells (A) and HuH-7 cells (B) using the lipofection method were stained with a FITC-labeled anti-fibrinogen antibody. Original $\mathrm{CHO}$ cells were used as a negative control and $\gamma \mathrm{N}$ Fbg-CHO cells $(\gamma \mathrm{N})$ as a normal control. Original HuH-7 cells or $\gamma \mathrm{N}$ Fbg-HuH-7 cells $(\gamma \mathrm{N})$ were used as a normal control. $\gamma 284 \mathrm{R}$ Fbg- $(\gamma 284 \mathrm{R}), \gamma 314 \mathrm{P}$ Fbg- $(\gamma 314 \mathrm{P}), \gamma 316 \mathrm{~N} \mathrm{Fbg}-(\gamma 316 \mathrm{~N})$, $\gamma \Delta$ G346-Q350 Fbg- $(\gamma \Delta), \gamma 366 \mathrm{~S}$ Fbg- $(\gamma 366 \mathrm{~S})$, and $\gamma 375 \mathrm{~W}$ Fbg-cells $(\gamma 375 \mathrm{~W})$ were shown. LG: scattered large granular form, F: fibrous form. Scale bar $=20 \mu \mathrm{m}$. The 
percentages of the 'LG', 'F', and normal forms were indicated under the photo.

Figure 4. Comparison of aberrant inclusion bodies between FSD- and FSD-non-inducing variant fibrinogen-synthesizing cell lines.

The percentages of the aberrant inclusion bodies, the ' $L G$ ' and ' $F$ ' forms, were plotted for stable variant fibrinogen-synthesizing $\mathrm{CHO}$ cell lines (A, open symbol) and transient variant fibrinogen-synthesizing $\mathrm{CHO}$ (open symbol) and $\mathrm{HuH}-7$ cell lines (closed symbol) (B). Six FDS- (FSD type) and seven FSD-non-inducible variant fibrinogen-synthesizing cell lines (Non-FSD type) were indicated as circles and squares, respectively. Medians and interquartile ranges depending on distributions were shown using a Box and Whisker plot on the left or right side of the symbols ( $\mathrm{x}$ represents the mean). The significance of differences between FSD- (FSD type) and FSD-non-inducible (Non-FSD type) variant fibrinogens was assessed by the non-parametric Mann-Whitney U-test $\left(*: p<0.05,{ }^{*}: p<0.01\right)$.

Figure 5. Electron microscopic observations of stable FSD-inducible variant fibrinogen-synthesizing CHO cell lines.

The sample for transmission electron microscopy was prepared and observed as 
described in the "Materials and Methods". $\gamma \mathrm{N}$ Fbg-CHO cells (A) as a normal control, $\gamma 284 \mathrm{R}$ Fbg- (B), $\gamma 366 \mathrm{~S}$ Fbg- (C), and $\gamma 375 \mathrm{~W}$ Fbg-CHO cells (D) showed the 'LG' form. $\gamma 314 \mathrm{P}$ Fbg- (E), $\gamma 316 \mathrm{~N}$ Fbg- (F), $\gamma \Delta \mathrm{G} 346-\mathrm{Q} 350$ Fbg- (G), and $\gamma 375 \mathrm{~W}$ Fbg-CHO cells (H) showed the 'F' form. The right upper panel of each photo (black scale bar $=200$ $\mathrm{nm}$ ) shows the magnification for the area indicated * in the main panel (white scale bar $=500 \mathrm{~nm})$. LG: scattered large granular form, F: fibrous form. N: nucleus, M: mitochondria, ER: endoplasmic reticulum.

Figure 6. Establishment of four types of CHO cell lines expressing $\gamma 375 \mathrm{~W}$.

Samples of CHO cell lysates were subjected to $10 \%$ SDS-PAGE under reducing conditions (A). Western blots were developed using an anti-fibrinogen antibody as described in the "Materials and Methods". Established CHO cell lines were stained with a FITC-labeled anti-fibrinogen antibody (B). CHO cell lines transfected with the $\gamma \mathrm{N}$ expression vector were used as a normal control (lower panels). Only $\gamma 375 \mathrm{~W}$ Fbg-CHO cells (upper panel, $A \alpha B \beta \gamma$ ) showed the two aberrant inclusion bodies, 'LG'; the large

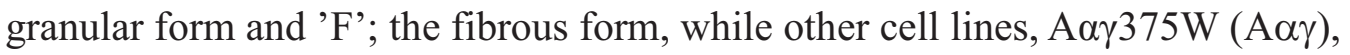
$\mathrm{B} \beta \gamma 375 \mathrm{~W}(\mathrm{~B} \beta \gamma)$, and $\gamma 375 \mathrm{~W}(\gamma) \mathrm{CHO}$ cells, stained positively for fine-granular forms and no aberrant inclusion bodies (upper panels). Scale bar $=20 \mu \mathrm{m}$. 


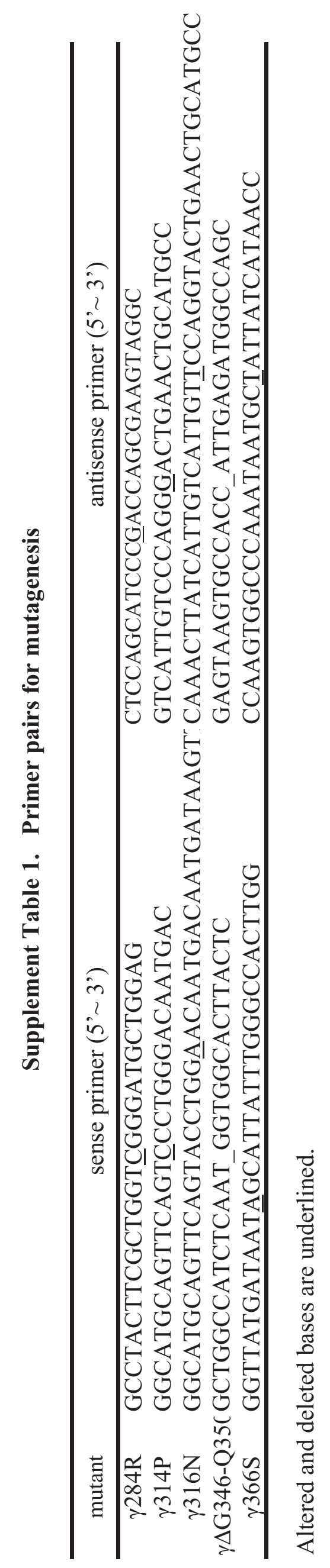



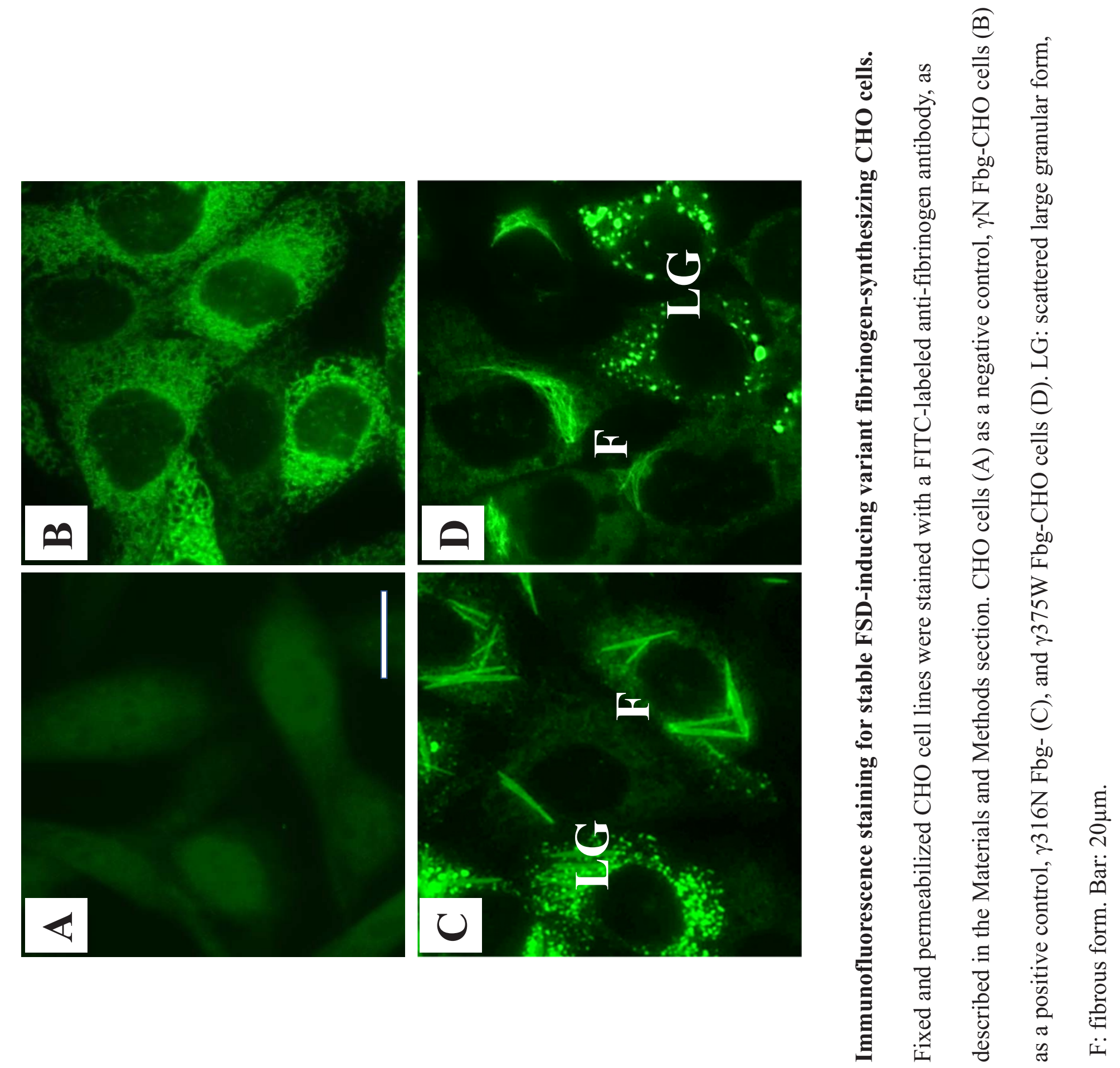


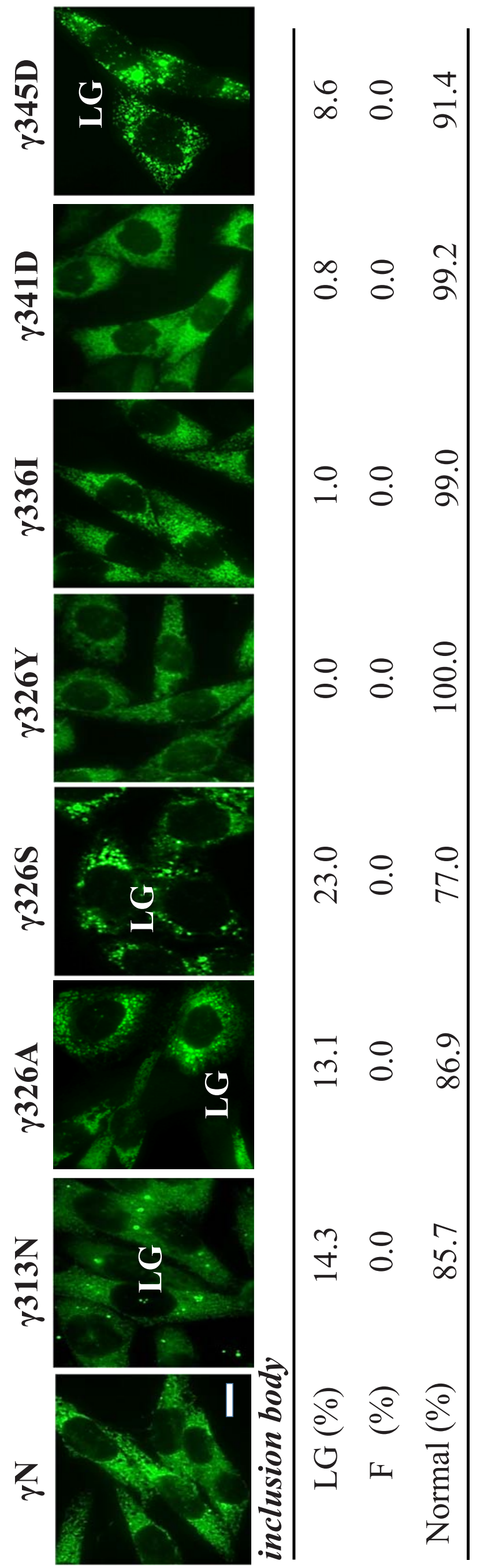




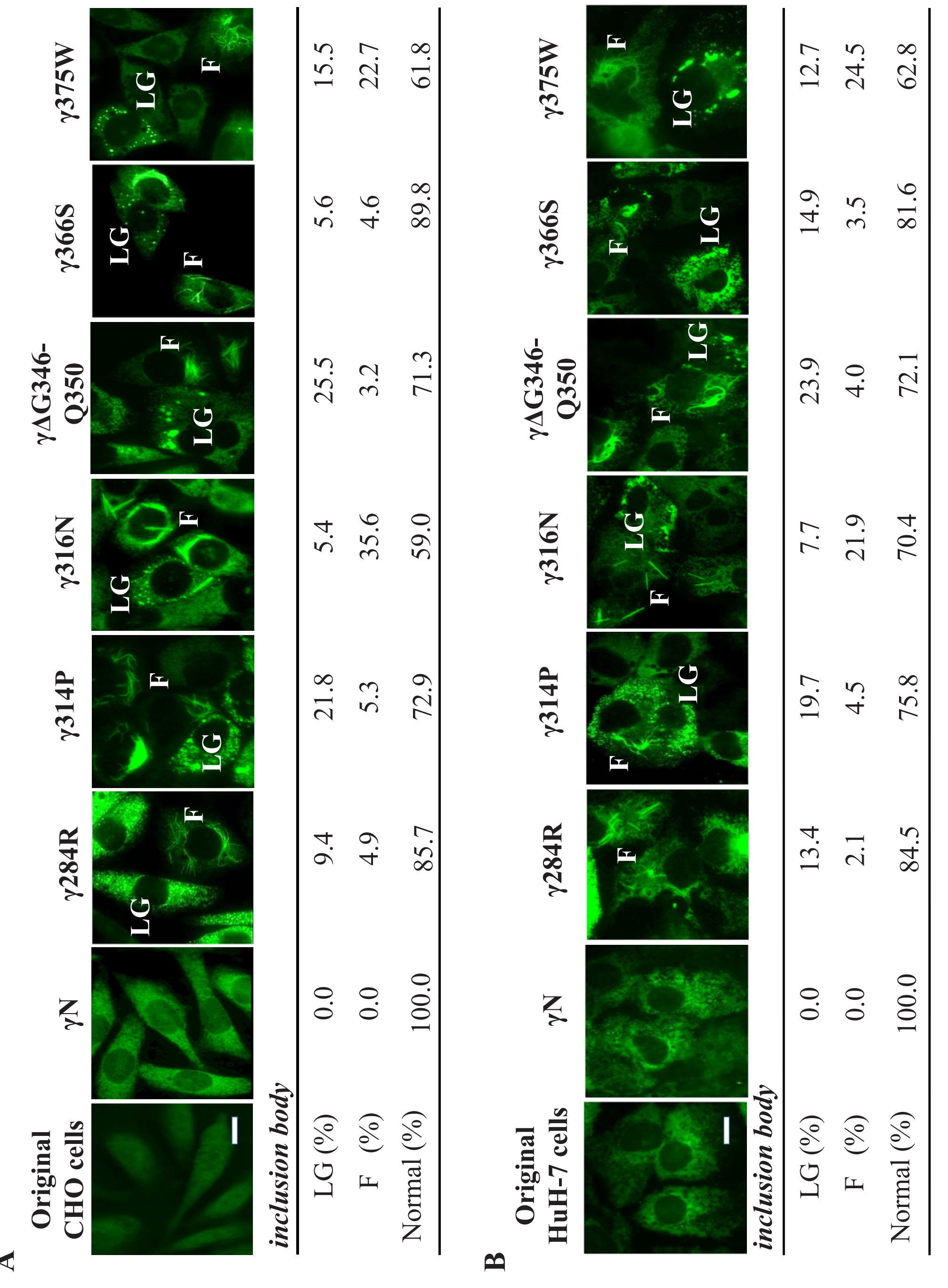


A : stable transfectants
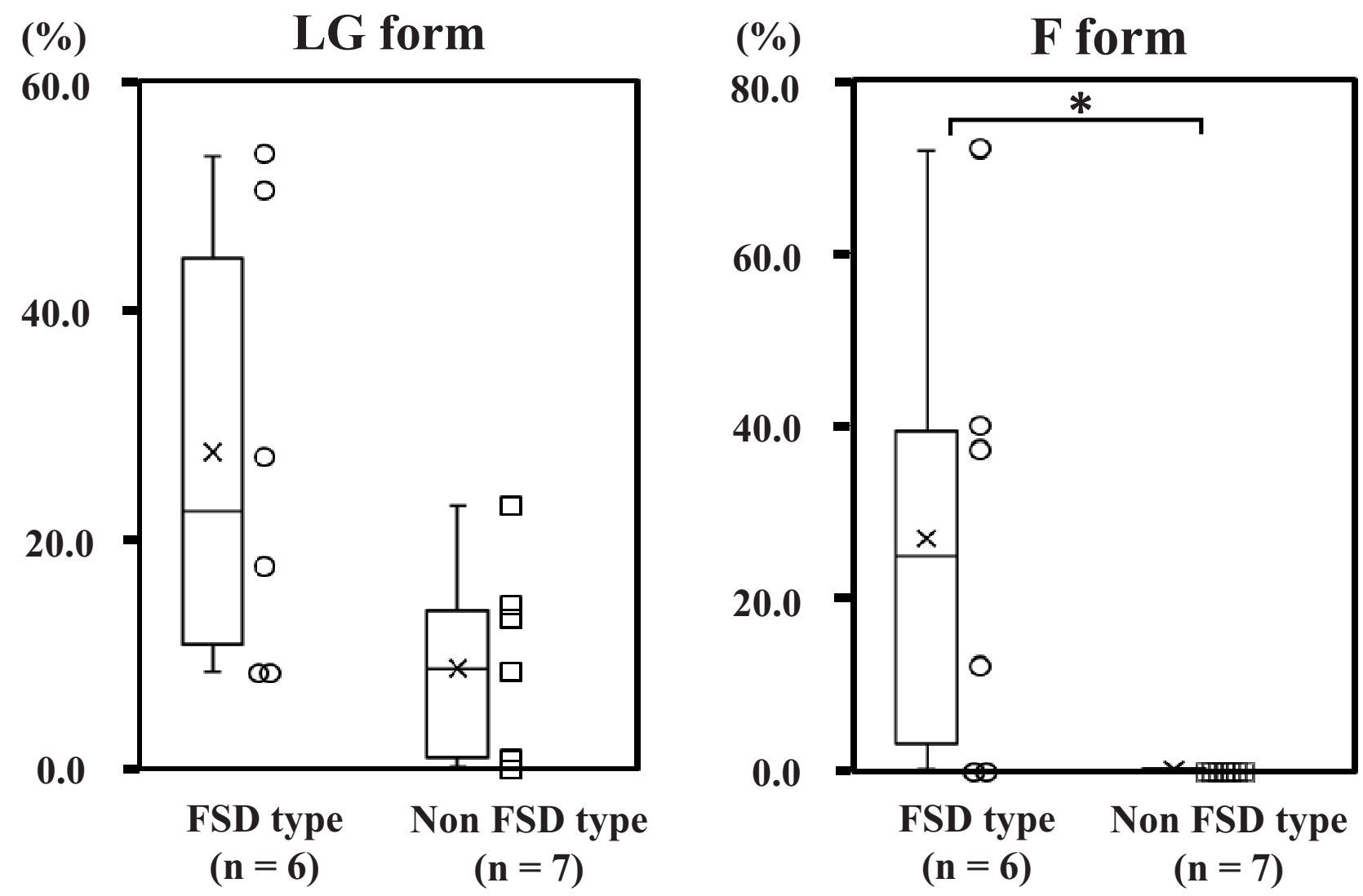

\section{B : transient transfectants}

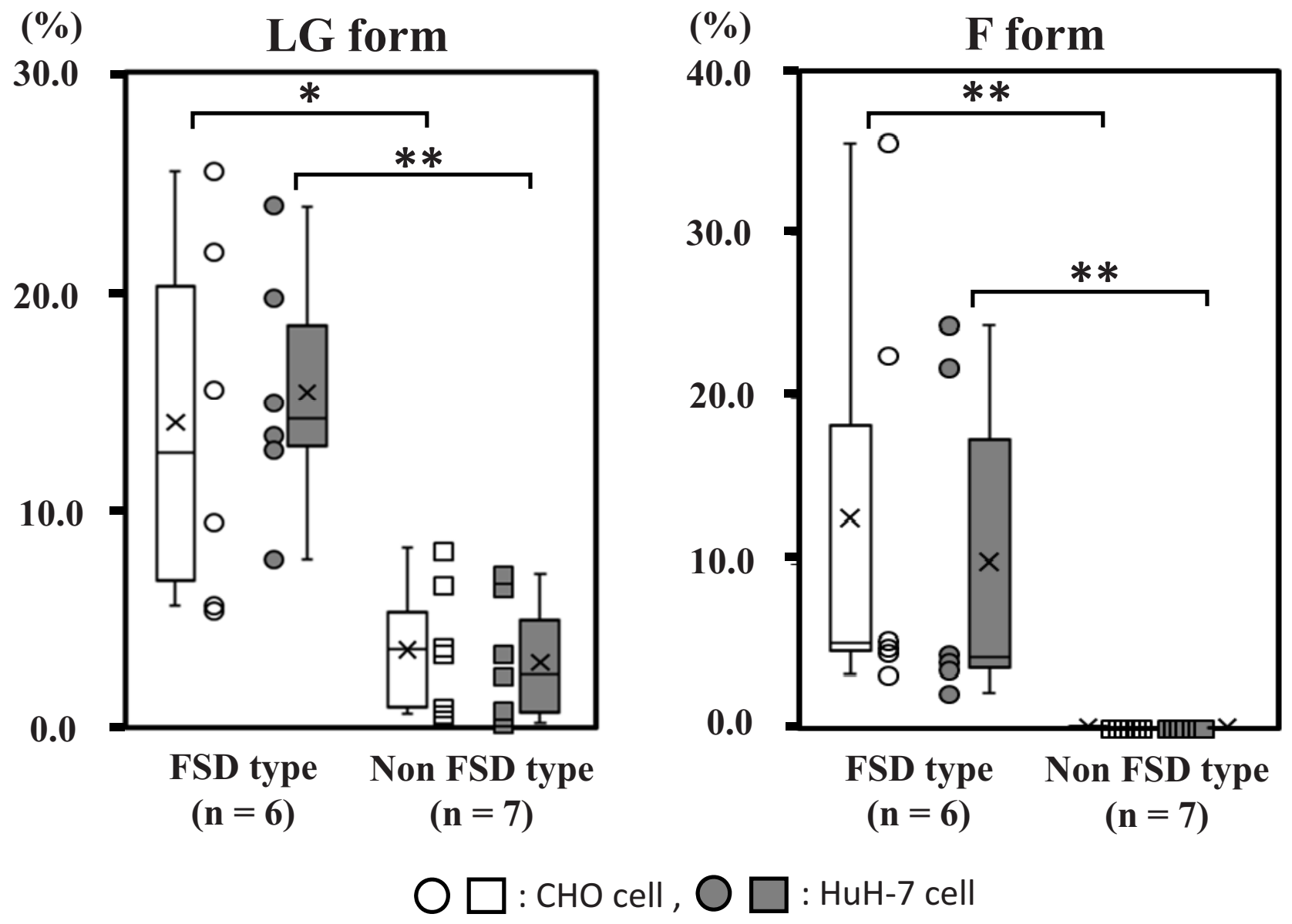



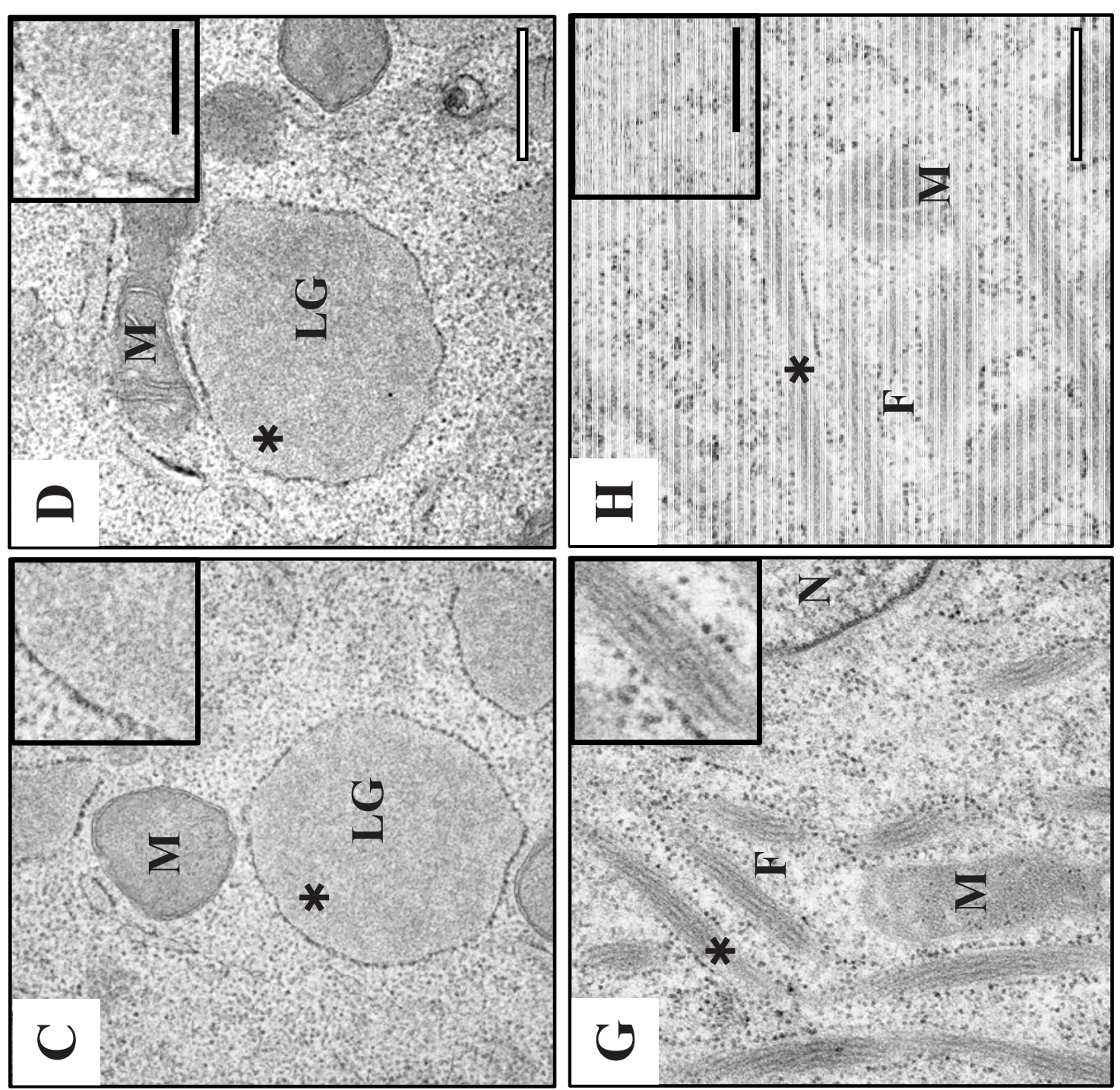

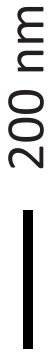
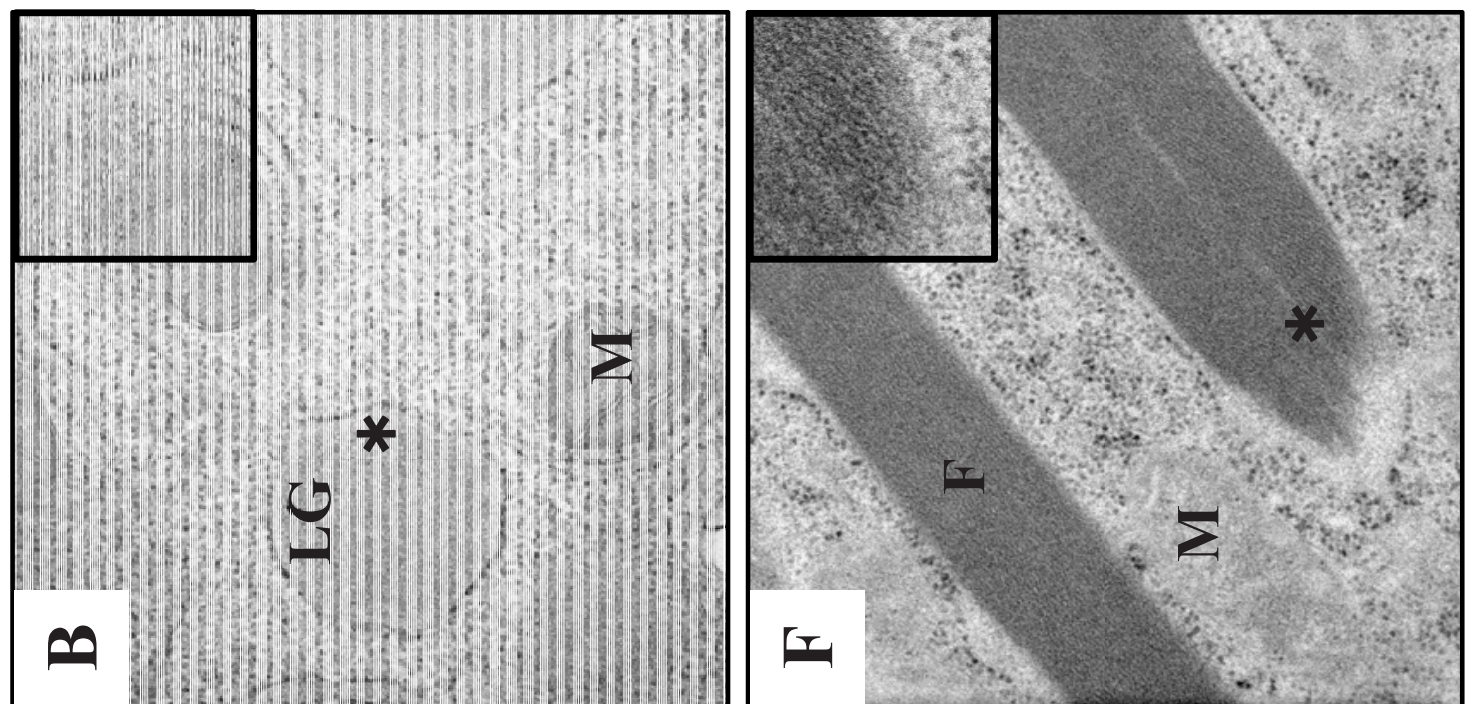

\begin{tabular}{l}
$\varepsilon$ \\
$\varepsilon$ \\
$\varrho$ \\
\hdashline \\
$\prod$
\end{tabular}
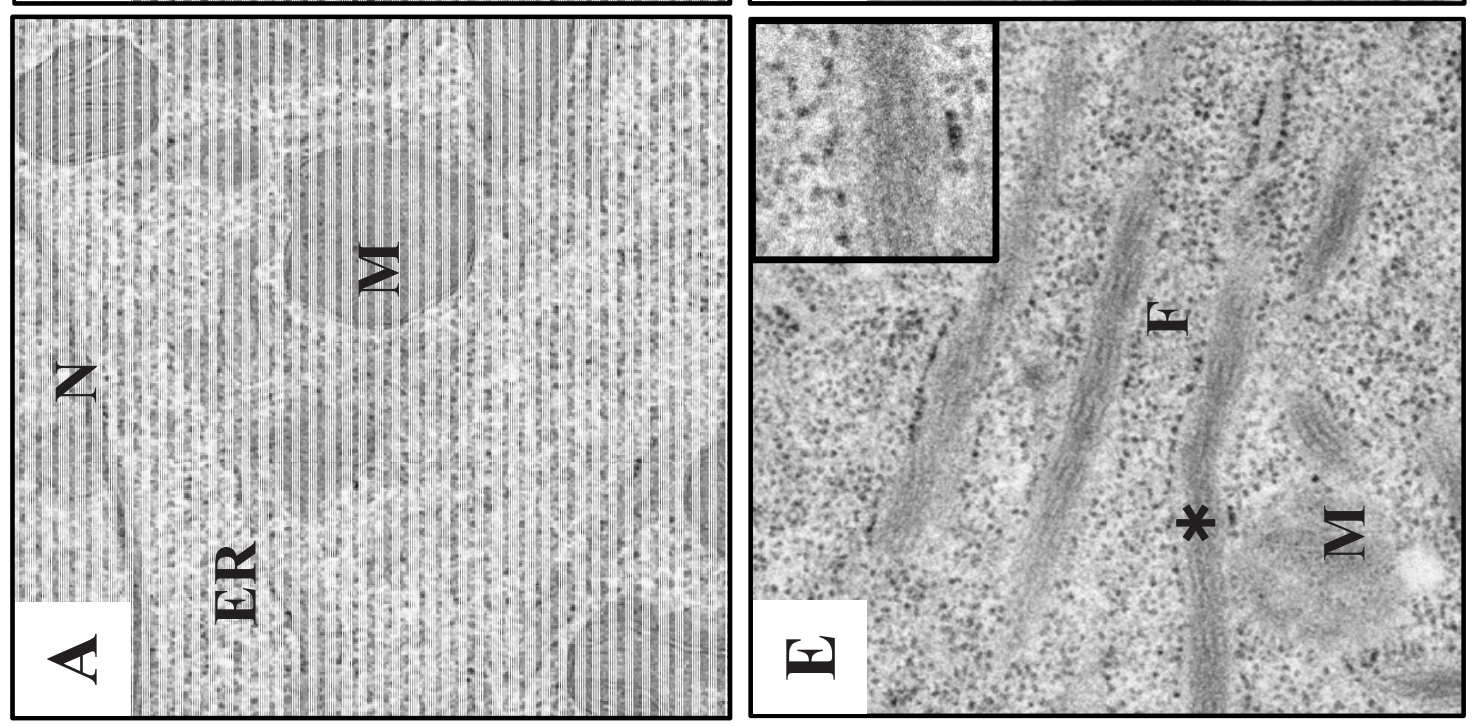

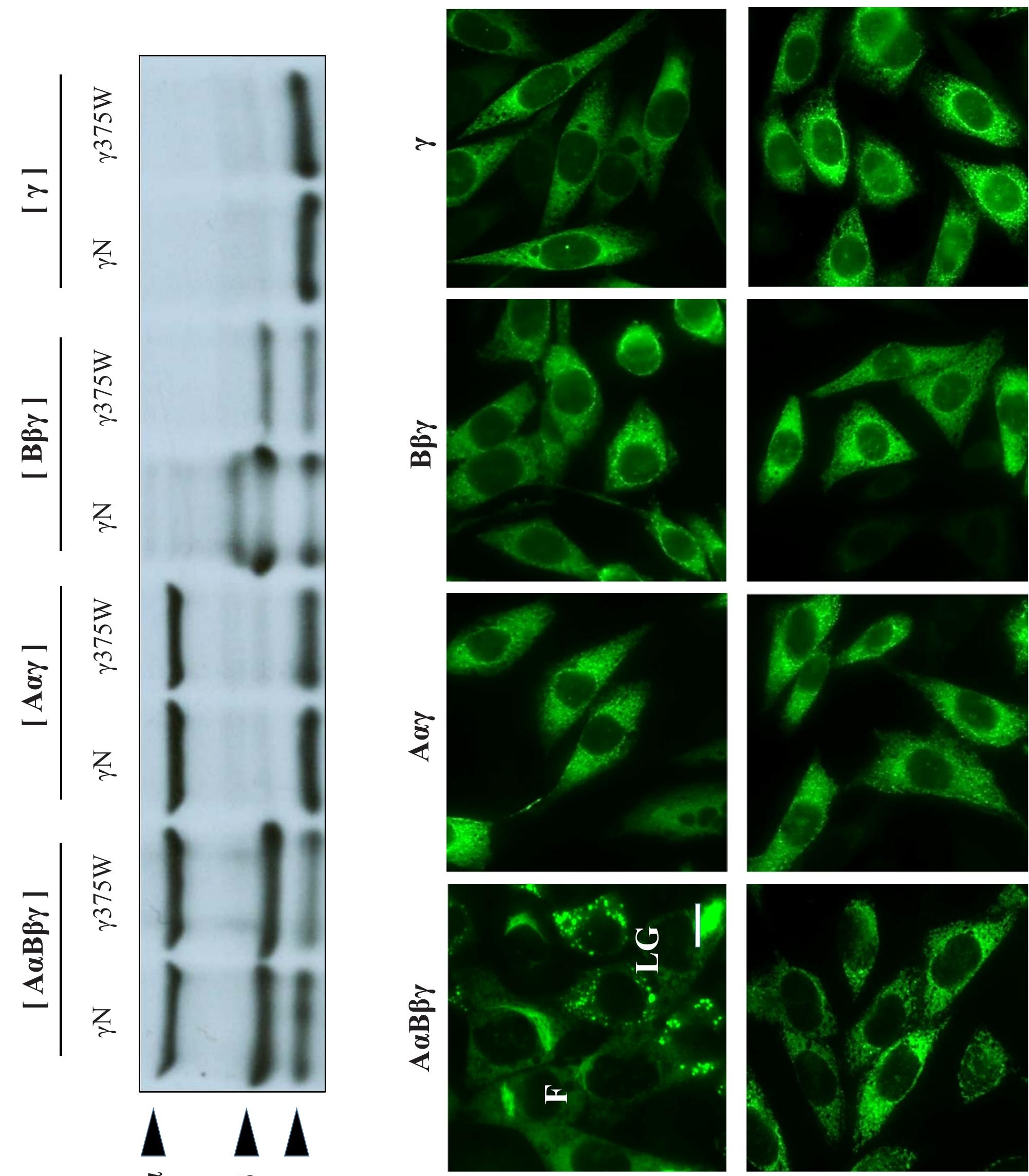
Table. 1 Reproducibility of the aberrant inclusion bodies in $\gamma 284 \mathrm{R}$ and $\gamma 366 \mathrm{~S}$ transfectants

\begin{tabular}{|c|c|c|c|}
\hline & stable $\mathrm{CHO}$ cells & transient $\mathrm{CHO}$ cells & transient HuH-7 cells \\
\hline \multicolumn{4}{|l|}{ y284R } \\
\hline LG $(\%)$ & $6.6 \pm 2.9$ & $11.4 \pm 5.1$ & $17.3 \pm 5.9$ \\
\hline $\mathrm{F}(\%)$ & $0.0 \pm 0.0$ & $3.4 \pm 1.8$ & $1.4 \pm 0.6$ \\
\hline Normal (\%) & $93.4 \pm 2.9$ & $85.2 \pm 3.6$ & $81.4 \pm 5.5$ \\
\hline \multicolumn{4}{|l|}{$\gamma 366 S$} \\
\hline LG $(\%)$ & $16.0 \pm 2.4$ & $11.4 \pm 10.1$ & $14.7 \pm 0.3$ \\
\hline $\mathrm{F}(\%)$ & $0.0 \pm 0.0$ & $3.1 \pm 1.4$ & $3.2 \pm 0.5$ \\
\hline Normal (\%) & $84.0 \pm 2.4$ & $85.5 \pm 9.1$ & $82.1 \pm 0.9$ \\
\hline
\end{tabular}

LG: scattered large granular forms, F: fibrous forms. 
Table.2 The frequency of aberrant inclusion bodies at FSD-non-inducible transient transfectants

\begin{tabular}{rccccccc}
\hline & $\gamma 3313 N$ & $\gamma 326 \mathbf{A}$ & $\gamma 326 S$ & $\gamma 326 Y$ & $\gamma 336 I$ & $\gamma 341 D$ & $\gamma 345 D$ \\
\hline CHO cells & & & & & & & \\
\hline LG (\%) & 3.7 & 6.5 & 3.4 & 0.4 & 0.9 & 0.6 & 8.1 \\
F (\%) & 0.0 & 0.0 & 0.0 & 0.0 & 0.0 & 0.0 & 0.0 \\
Normal (\%) & 96.3 & 93.5 & 96.6 & 99.6 & 99.1 & 99.4 & 91.9 \\
HuH-7 cells & & & & & & & \\
\hline LG (\%) & 2.4 & 6.4 & 3.4 & 0.2 & 0.5 & 0.8 & 7.0 \\
F (\%) & 0.0 & 0.0 & 0.0 & 0.0 & 0.0 & 0.0 & 0.0 \\
Normal (\%) & 97.6 & 93.6 & 96.6 & 99.8 & 99.5 & 99.2 & 93.0 \\
\hline
\end{tabular}

LG: scattered large granular forms, F: fibrous forms. 